\title{
Dos "índios gays" ao queer como crítica colonial: Uma agenda para o embate ${ }^{1}$
}

\section{From "gay Indians" to queer as colonial critic: An agenda to the struggle}

\author{
Estevão Rafael Fernandes \\ Universidade Federal de Rondônia - UNIR \\ Universidade Federal de Mato Grosso - UFMT \\ e-mail: estevaofernandes@gmail.com
}

\section{Resumo}

Este texto, baseado em uma conferência sobre "Diversidade Sexual e de Gênero Fora dos Eixos" busca problematizar alguns aspectos epistemológicos e políticos de se trabalhar com a temática "homossexualidade indígena". Propõe-se aqui, ainda que de forma experimental, um olhar a partir do qual seja possível uma crítica ampliada não apenas a questão da sexualidade e do gênero, mas a questões políticas e discursivas, desde e para as "fronteiras" dos eixos temáticos e abordagens hegemônicos.

Palavras-chave: Queer, colonialismo, sexualidades indígenas.

\begin{abstract}
This text, based on a conference about "Sexual Gender Diversity and Out-of-Axis", seeks to problematize some epistemological and political aspects of working with the theme "indigenous homosexuality" in contemporary Brazilian anthropology. It is proposed here, albeit experimentally, a view from which a critique can be extended not only to the question of sexuality and gender, but also to political and discursive issues, from and to the "boundaries" of the thematic and hegemonic approaches.
\end{abstract}

Keywords: Queer, colonialism, native sexualities.

Há alguns anos venho trabalhado com um tema ao qual tenho denominado, de modo mais ou menos genérico, como "homossexualidade indígena"2. De um começo mais ou menos solitário, fico satisfeito em perceber que não apenas a pesquisa tem encontrado alguma repercussão fora dos restritos eixos acadêmicos mas, sobretudo, que ela se encaixa em um campo mais amplo, praticamente invisibilizado - por não fazer parte da agenda dos tantos "donos" (ao menos eles se veem assim!) da temática do gênero nas Ciências Sociais do país. Estranho trabalhar com uma categoria que é, em

\footnotetext{
${ }^{1}$ Conferência magna proferida na 6a . Edição do Antropologia em Foco, organizada pelo Programa de PósGraduação em Antropologia da Universidade Federal do Pará entre 24 e 26 de outubro de 2017. Agradeço desde já aos pareceristas de Interethnic@ pelos comentários e sugestões.

${ }^{2}$ Para um panorama geral da trajetória até aqui, sugiro Fernandes, 2017.
} 
si mesmo problemática - não é de hoje que autores se perguntam sobre a capacidade heurística da categoria "homossexualidade indígena" para referir-se a esse conjunto de fenômenos ${ }^{3}$. Dentro desse campo "invisível" encontram-se, também, vários estudos feitos sobre sexualidades rurais, quilombolas, ribeirinhas, interioranas, ... aquelas para as quais, no fim das contas, o exercício de contorcionismo (in)capaz de inseri-los na agenda teórica euronorcêntrica simplesmente não vale o trabalho e a dor de cabeça.

Me refiro, sobretudo, a dossiês sobre "Diversidade sexual e de gênero em Áreas rurais, contextos interioranos e/ou situações etnicamente diferenciadas: Novos descentramentos em outras axialidades", publicados na revista Aceno - Revista de Antropologia do Centro-Oeste (UFMT)volume 3, número 5 e Amazônica - Revista de Antropologia (UFPA) volume 8, números 1 e 2 , nos quais se vê como essas temáticas passam quase despercebidas no mainstream dos programas de Disciplinas e eventos mais centrais no âmbito da Disciplina ${ }^{4}$. Verdade seja dita, todo Antropólogo já "iniciado" conhece, mesmo que por auto, alguma história que não deveria ser contada sobre temas e abordagens malditas sobre as quais, tal qual Voldemort, dos livros Harry Potter, não se pode falar a respeito ou nominar. Sim, antropólogos não apenas estudam tabus, como estão certamente presos a vários - neste sentido, o bom de escrever desde e para as periferias, sobre um desses temas voldemortianos é que estamos longe do universo no qual brigas de ego ou por "objetos" da disciplina podem fazer algum sentido.

Nossa alternativa, nestas margens, não é o de fortalecer um discurso de vira-latas, ou uma política de autorrepresentação esquizoanalítica, desde a qual falamos de nós para nós mesmos, num eterno jogo de espelhos. De espelhos e narcisos a academia já está cheia, diga-se desde já. $O$ que contrapomos, desde estas periferias, é um sistema que nos prenda à condição de objetos, fechando qualquer possibilidade epistemopolítica ${ }^{5} \mathrm{de}$ uma renovação disciplinar a partir de formas de pensamentos-outros, fora dos manuais e para além de algumas práticas que levam nossa intelligentsia a supor que o Brasil de hoje, em início de 2018, é um contexto democrático e aberto ao diálogo e à tolerância. É chegado o momento de uma antropologia combativa e descentrada.

Talvez a temática que eu estudo seja ilustrativa nesse sentido. Nunca me dei o trabalho - talvez por falta de tempo e/ou disciplina - de tentar

\footnotetext{
${ }^{3}$ Cf Mott, 2015.

${ }^{4}$ Seria impossível nominar aqui, individual e isoladamente as dezenas de contribuições enviadas para esses volumes. Contudo, penso ser possível toma-los como conjunto, enquanto movimento de revolvimento no campo dos estudos da sexualidade no país.

${ }^{5}$ Sobre isso, ver Fernandes, 2014
} 
desenvolver, teoricamente, qual as implicações heurísticas, éticas, filosóficas ou antropológicas de se aplicar a ideia de "homossexualidade" aos povos indígenas. Uso "homossexualidade" como termo genérico, guarda-chuva, para me referir a todas as formas de sexualidade referidas na literatura etnográfica e histórica por nomes como "sodomia", "pederastia", "perversões", "pecado nefando", etc. Mais que isso, uso "índio gay" como categoria política mais do que preocupado com as implicações epistemológicas de seu uso - como se episteme e política fossem dois campos separados do conhecimento... assumir-se como gay, em aldeias, é muitas vezes um ato político ${ }^{6}$, assim como assumir-se como indígena, fora delas. Ao ser enxergado por si, pela comunidade e pela sociedade envolvente como gay, o indígena também é enxergado a partir da carga de preconceitos e estigmas que o termo carrega - me refiro aqui aos gays, mas a argumentação se estende ao universo LGBT, como um todo.

Veremos isso adiante, mas um exemplo preliminar disso são os indígenas que vêm estabelecendo contato comigo, buscando saber como obter meus livros ou artigos, a fim que possam mostrar para suas lideranças, como meio de mostrar que o fato de serem gays, lésbicas ou trans não os torna menos indígenas. Nesta fala - a quem, de forma tão simpática, a coordenação do evento resolveu chamar de "Conferência" -, buscarei tentar falar não sobre o que entendo ser homossexualidade indígena mas, sobretudo, quais as implicações e complicações de se trabalhar e pensar a partir dela. Sempre imaginei que um bom trabalho de pesquisa é aquele que lhe suscita questionamentos que não existiam antes de ser lidos, mas do que dar respostas.

As questões epistêmicas, justamente por serem políticas, neste sentido, não dizem respeito às implicações heurísticas do termo, ou aos anacronismos, etnocentrismos e eurocentrismos, mas à necessidade de se tratar de questões não ditas, não discutidas, não pensadas porque pensadas em outros termos, ditadas por outras pessoas, em outros contextos para outros contextos.

Pensar em temas como esse são importantes justamente para nos obrigar a sair das caixinhas reprodutivistas, tão caras a setores específicos da academia hegemônica, a trabalhar com tema Do velho esquema disciplinar e das autocitações, como se nossas caixinhas fossem suficientes e alheias às brigas de egos e disputas internas aos campos acadêmicos.

\footnotetext{
${ }^{6}$ Sugiro a leitura da reportagem de Sofia Amaral, "Os jovens indígenas querem incluir o debate LGBT em sua luta" publicada pela agência Pública em 02 de fevereiro de 2018, disponível aqui em http://bit.ly/2sIWPV0 (acessada em 22 de fevereiro de 2018).
} 
Por razões que ficarão mais claras adiante, essas questões me levaram a me questionar sobre colonialismos, em suas múltiplas formas.

Nesse sentido, tenho dito, sempre que posso, que a discussão sobre colonização - e me refiro aqui às múltiplas formas de colonização cotidianas, às diversas técnicas e instrumentos desde os quais não se diz, não se fala, não se ouve, e se apagam os silenciamentos em sua multiplicidade, pois assim como silêncio é algo que vem no plural, violências, dominações e apagamentos se dão no plural, a fim de apagar o diferente, tornando sua desigualdade algo naturalizado.

Como antropólogo desaprendi a compreender o que é cultura, tornando mesmo os múltiplos contextos em que tal fórmula é constantemente repetida em algo político. Tudo o que é cultural é político. Tudo o que é social é político. Tudo o que é natural, desnatural, antinatural, sobrenatural: são categorias políticas. A questão, dizia Humpty Dumpty à Alice em Alice através do Espelho, é descobrir quem manda... e, quem manda quando se trata de colonizações, no plural? É disso que pretendo falar aqui, sobre processos de silenciamento.

O colonialismo, como eu dizia, é um processo - ainda vivo e pulsante, veremos isso adiante - tem um duplo pressuposto.

O primeiro é o de reduzir o colonizado a uma nota de rodapé de sua própria história. O pós-colonial - onde "pós" opera como um "além" ou "fora de" parte de um lugar no qual é possível uma contra-narrativa fora das categorias impostas histórica, social e epistemicamente, na, pela e para a manutenção das relações coloniais. Esse lugar possui vários nomes, dependendo do conjunto de autores aos quais podemos recorrer, mas a ideia é de uma margem, um local onde haja a possibilidade de uma existência do "eu" a partir do qual seu sotaque, sua língua, sua cor, seus afetos, suas referências, não sejam "as" erradas. O pós-colonial existe, por assim dizer, para dar vez e voz aos sujeitos que não se sentem incluídos ou representados nas grandes narrativas. Trata-se de tirar "quem manda" do lugar de enunciação privilegiado a fim de desvelar esses privilégios e, assim, contrapô-los.

Como indicamos acima, o pós-colonial é o espaço a ser ocupado pelo colonizado que não seja o de uma nota de rodapé de sua própria história, culpabilizado eternamente por seus próprios fracassos na tentativa de se enquadrar no modelo de modernidade liberal ocidental, nos padrões, no imaginário autoimagético do colonizador. Desta forma, oferece um lugar de contestação, reorientação e transformação à lógica da exploração, subordinação e invisibilidade. Novamente, é importante que se diga, aqui, 
que o pós-colonial não é nem uma renúncia ou negação do ocidente, bem como um conjunto de teorias que se encontre em um passado histórico, morto e enterrado: é um olhar desde as margens e fronteiras, não pensando as periferias como um sub-lugar, mas pensar uma outra noção de lugar, de fala, de pensar. Uma forma bastante interessante de pensarmos as relações pós-coloniais é como um feixe de relações - políticas, ontológicas, sociais, ... - emaranhadas internamente, funcionando estruturalmente em conjunto, ainda que possam ser enxergadas, vez ou outra, a partir de suas partes.

O segundo é o de incutir no colonizado a ideia de que sua própria colonização, apagamento e subalternização são um favor ao colonizado: libertá-lo da condição de ser o que é, para torna-lo num simulacro, num não ser preso a um não lugar é do que se trata a colonização. A colonização é, do ponto de vista da sociedade hegemônica, uma grande narrativa unilinear e teleológica não apenas de apagamento, mas de justificação para esse processo, como se o colonizador estivesse libertando o colonizado do julgo de ser si mesmo, deixando com que ele fosse, no processo, sujeito de seus próprios desejos, ações, conflitos e representações. O colonizador conta sua história como se fosse um narrador onisciente: nossa motivação foi chamar a atenção para os não ditos nessa narrativa, para os espaços em branco entre as linhas. Como já tive ocasião de afirmar, os silenciamentos tornamse naturalizados: mais do que se perguntar "Por que" isso ocorre talvez seja uma questão de compreender "como" isso ocorre e de que maneiras esses processos de subalternização e silenciamentos dão sentido à própria ordem colonial. No caso indígena, por exemplo, é impossível descolar essas questões da incorporação compulsória da mão de obra indígena ao sistema de exploração hegemônico. Autores como Fanon (2008, 2011), Cesaire (1978) e Anzaldúa (2005), por exemplo, deixam claro como esse processo de esvaziamento de si é parte fundamental do processo de colonização, de tal modo que estas questões acabam ultrapassando as fronteiras das discussões sobre indígenas para nos ensinar sobre racismo, colonialismo epistêmico, "coxinhas" e batedores de panelas, etc 7 .

Uma das bases do sistema colonial é, justamente, estruturar-se (ideológica e institucionalmente) no sentido de tentar incutir, no "outro", a ideia de que a diferença é algo a ser anulado e apagado - não para a manutenção do poder desde o polo hegemônico, mas como um gesto de grandeza e gentileza para com o subalternizado.... Assim, "cura-se" o gay: não porque sua existência deixe evidente as contradições de um sistema moral

\footnotetext{
${ }^{7}$ Para situar e ampliar essas críticas, cf. Fernandes, 2016.
} 
heteronormado e violento, mas para "salvá-lo" do inferno. Se constroem usinas sobre terras indígenas: não porque haja conglomerados financeiros e interesses diversos de políticos, empresários, etc., mas para trazê-los ao "progresso"... "Veja bem" - dizem as instituições hegemônicas desde perspectivas científicas, religiosas, ideológicas - "você não tem culpa por ser negro, nordestino, indígena,... por professar uma religião de matriz africana, por morar na Amazônia... e, por você não ter culpa lhe ensinarei, impondo meus valores morais, religiosos, raciais, econômicos, filosóficos, epistemológicos como falar certo, agir certo, a abandonar esse "sotaque esquisito", essas roupas, essas "crenças" para se tornar o que eu sou"... é como se a única saída possível fosse se adequar ao sistema hegemônico, se enquadrar. Depois disso tudo ser imposto, cabe ao dominado entender que, por mais que ele tenha lutado - daí a importância na crença liberal da meritocracia, outra falácia na moda nos círculos conservadores - ele não conseguiu se tornar aquilo que se tentou fazer com que ele se tornasse. Daí porque lutas contra racismos, lgbtfobia, ultranacionalismos, etc. são tão importantes: elas representam mais do que a resistência a uma lógica de opressão econômica e/ou ideológica, mas a luta pelo próprio direito de res/ex-istir.

A história nos mostra que por 500 anos, por exemplo, se impôs a indígenas que buscassem se transformar em brancos - e não qualquer branco: 0 branco subalternizado, o camponês pobre, mas cristão, monogâmico, hetero e "cidadão de bem", consumidor e bom pagador de impostos. Tudo isso para seu próprio bem... Esse apagamento das diferenças é algo perigoso, pois, a partir daí, tolhe-se o direito a existências diversas daquelas aceitas desde a lógica hegemônica... A existência desses "outros" põe em xeque as estruturas desde as quais esses dispositivos hegemônicos se sustentam eis aí porque esta ânsia em se apagar estas formas outras de ser, saber, res/ex-istir.... Temos aí um ponto de toque entre noções como colonização e abjeção, e desde aí uma crítica epistemopolítica poderosa ao racismo e a heteronormatização compulsória como políticas de Estado - algo pelo qual alguns setores de nossas elites têm demonstrado um tremendo fascínio nos últimos tempos.

Façamos aqui um parêntesis.

Como disse antes, há alguns anos venho me dedicado a trabalhar com um fenômeno mais ou menos conhecido, de forma genérica, como "Homossexualidade indígena" - categoria usada como lugar de enunciação político. Os indígenas que se percebem como gays, lésbicas, trans,... em geral, se veem assim em um contexto no qual a heternormatividade já foi ensinada e gradualmente imposta em suas aldeias, vidas, seres e corpos. De 
que forma isso opera? Digo que a homofobia chegou aqui de caravela, e que a heteronormatividade compulsória foi - e é - uma das técnicas do colonialismo: a submissão do desejo do outro ao meu, colonizado, é parte do processo colonial. De modo geral, raça, saber, sexualidades, classe, controle do trabalho, dentre outros, tornam-se elementos indispensáveis para compreender o conjunto das questões apresentadas aqui ${ }^{8}$. Desta forma, ao propor a chave interpretativa da "colonização das sexualidades" indígenas, tenho buscado chamar a atenção para como ações cotidianas como nomear, vestir, cortar o cabelo, divisão do trabalho etc., dizem respeito necessariamente à imposição de um novo padrão de moral baseado no modelo binário e cristão hegemônicos, dentro de uma lógica de exploração e subordinação.

Nesse contexto, sem dúvida, ser o sujeito do próprio desejo é uma atitude anticolonial. Como isso opera? Não podemos pensar - e a nós, que vivemos, moramos e pensamos nas, das e para as fronteiras e bordas dos eixos pelos quais o conhecimento "legítimo" é construído, constituído, consolidado e reproduzido - que o colonialismo seja uma mera abstração, ou um conceito utilizado aqui ou ali por intelectuais palestinos, indianos, europeus, americanos, quase sempre pautados e calcados em pensadores da moda e articulados como que para abençoar as discussões desenvolvidas neste ou naquele campo ${ }^{9}$ ou - prestem atenção - Disciplina.

Cheguei a estas (in)conclusões depois de me deparar, durante meu Doutorado, com a necessidade de ter um objeto de pesquisa. No começo do curso, em uma disciplina sobre gênero na América Latina, me chamou a atenção a falta de uma bibliografia mais sistemática sobre sexualidades indígenas fora do modelo heteronormado. Em casa, pesquisando sobre o tema, vi referências sobre o tema na imprensa do Brasil quase sempre se referindo à homossexualidade indígena pela perspectiva do preconceito sofrido por esses sujeitos em suas comunidades, quase sempre acusados de estarem "perdendo sua cultura". Como o Ceppac/UnB (atualmente ELA/UnB), onde eu fazia o Doutorado, era um Centro de Pesquisa e PósGraduação no qual se exigia uma tese que tratasse de estudos comparados sobre as Américas, resolvi buscar compreender como a questão era vista em outros países, me deparando com os two-spirit dos Estados Unidos e

\footnotetext{
${ }^{8}$ Nota-se aqui uma aproximação com a noção de Colonialidade...? (ver próxima nota de rodapé)

9 ... que finda aqui. Tenho, particularmente, um pé atrás com modelos macro-explicativos e genéricos demais. Podemos, sim, olhar para a realidade social e tentar interpreta-la a partir dessas matrizes, mas é importante o movimento de volta, ou seja: o que os processos empíricos, os micro-poderes, as relações cotidianas, os não ditos, etc., podem nos informar sobre tais modelos a fim de serem aprimorados, sistematicamente? Esse "movimento de volta" certamente é algo a ser feito a fim de que críticas pós-coloniais, decoloniais e anticoloniais possam fazer frente ao dinamismo das relações sociais postas em jogo pelos poderes coloniais e por suas inter-relações internas e intrínsecas.
} 
Canadá. Assim, a experiência indígena norte-americana é bastante interessante. Lá, como cá, sexualidades fora do modelo predominante foram também perseguidas por portugueses, ingleses, franceses e espanhóis. Diversas denominações foram utilizadas para se referir a esses indígenas, quase sempre com uma forte carga estigmatizante ("berdache", por exemplo, termo de uso corrente até bem recentemente entre antropólogos, tem sua origem em uma expressão árabe, que se refere ao menino submetido a relações de pederastia). Ao longo dos anos 80 , quando os indígenas começam a ser infectados com HIV e retornam às suas aldeias para morrer com suas famílias são, em princípio, rechaçados por sua comunidade. De um modo geral, a acusação era de que eles seriam soropositivos por serem "degenerados", uma vez que teriam abandonado suas culturas e se tornado gays, devido ao contato com o não-indígena. Sua resposta viria como uma crítica ao aparato colonial moldada a partir de uma identidade pan-indígena e amparada por um discurso espiritual.

Em sua própria visão, eles não teriam abandonado suas culturas, ao contrário, seriam parte de uma tradição de diversos povos nativoamericanos de pessoas two-spirit - em uma tradução livre, aquele/a com dois espíritos. Assim, eles não seriam "gays", mas pessoas de dois espíritos (de homem e de mulher), estando em transição entre os dois mundos: masculino e feminino, espiritual e terreno, indígena e não-indígena, o que lhes garantiria um papel de destaque em seus povos. Um exemplo disso seria We'wha, indígena Zuni que chegou a encontrar-se com o presidente Grover Cleveland no final do século XIX, passando seis meses em Washington. Assim, na década de 80 surgem diversas organizações twospirit no Canadá e nos Estados Unidos e, em 1990, após um encontro em Winnipeg, esse/as indígenas passam rechaçar qualquer outra denominação (como "berdache", por exemplo).

$\mathrm{Na}$ prática, isso significaria mais que uma simples mudança de denominação: assumir-se como dois espíritos não apenas focava no papel espiritual da pessoa (e não em suas práticas sexuais) como também significa uma crítica ao processo de colonização: parte considerável dos escritos produzidos por autores e ativistas two-spirit se assenta na análise e crítica aos processos de colonização que os estigmatizaram. Além disso, essas lideranças se viam diante do desafio de se consolidar como grupo autônomo e com agenda própria, estando à margem dos movimentos indígena e LGBTIQ. Cabe notar que o movimento indígena não lhes dava espaço, por serem homo/bi/transexuais; tampouco o movimento LGBTIQ lhes dava voz, por serem indígenas. 
Trata-se de se contrapor o colonialismo e o processo de colonização não como algo do passado, morto e enterrado, tampouco focando suas críticas em "caixinhas" como sexualidade, gênero, etnicidade, movimentos sociais, religião, corpo... Essa separação faz sentido e dá sentido em nossa epistemologia, ou, melhor dito, na forma de construção de conhecimento que temos por legítima. Trata-se de se descolonizar o imaginário, a memória...

Se não é uma mera abstração, como o colonialismo impôs aos povos indígenas seu modelo de moral, desejo e sexualidade?

Coube ao colonizador o papel de enquadrar a sexualidade indígena em suas várias formas - o que os jesuítas chamavam de sodomia, a poligamia, 0 casamento entre parentes, etc. - com diversas outras práticas como a nudez, antropofagia e o politeísmo, por exemplo. As cartas jesuítas são repletas de trechos nas quais eles se referiam às aldeias tupinambás da costa brasileira como visões do inferno, com cheiros e sensações dignas de satanás. Falamos de um contexto no qual tudo era utilizado para transformar aquelas nações em súditos bem-comportados da coroa: bons cristãos, monogâmicos, obedientes e que só copulariam para reproduzirem - gerando pequenos súditos tão comportados e ciosos, moralmente, quanto eles. Percebemos, por essas fontes, um policiamento ostensivo das sexualidades indígenas a fim de normalizá-las em um processo dialético: a representação dessas práticas enquanto algo pecaminoso, degenerado, involuído, etc. não apenas legitimava sua repressão, como também dava sentido aos sistemas de ideias de onde partiam essas representações: a subordinação do desejo do outro à vontade do colonizador passava a ser algo central no sistema de dominação colonial e na justificativa para sua própria existência. Trata-se de se lançar alguma luz sobre processos de heterossexualização compulsória daqueles povos, tendo por base pressupostos científicos, teológicos, sociais e culturais e a partir de dispositivos articulados aos discursos e práticas religiosos, civilizatórios, acadêmicos e/ou políticos. Ou seja: as formas pelas quais lhes foi imposta uma sexualidade "normal" deve ser compreendida em paralelo com as noções teológicas, filosóficas, científicas etc., a partir das quais os índios eram (e são) compreendidos no Brasil pelos setores hegemônicos da sociedade colonizadora.

Além disso, o uso do termo "colonização" para fazer referência ao processo de colonização das sexualidades indígenas não é gratuito. Ao usar o termo deixa-se claro uma leitura crítica da práxis colonizadora enquanto processo político, cuja finalidade era (e segue sendo), a partir de um jogo de poder calcado na imposição, na violência e na assimetria de forças, incorporar os 
povos indígenas ao sistema econômico hegemônico. Os indígenas não eram urgidos a se casarem com os colonizadores ou a reconstruírem suas aldeias aos moldes do não-índio, ao lado de presídios, internatos, igrejas, quartéis etc. pela benevolência do colonizador - ainda que suas justificativas, morais ou acadêmicas se pautassem nesse discurso - mas, sobretudo, guiados por seus próprios interesses: ter mão de obra disponível, braços para a defesa territorial, livrar terras para aproveitamento econômico etc. - importa chamar a atenção aqui, uma vez mais, para o fato de que tais processos não se restringem aos povos indígenas, somente.

Devemos lembrar, por exemplo, que o próprio conceito de Sodomia para se referir às práticas sexuais entre pessoas do mesmo sexo apenas surge no século XI para se referir à uma ideia de que a cada pecado equivale uma retribuição divina. Pecado e obediência é, sabemos ainda hoje, o binômio por trás da lógica e da justificativa para demonizar, literalmente, as práticas homodesejantes. Contudo, na época em que falamos em consolidação dos Estados Ibéricos, a ideia de "sodomia" foi incorporada pela coroa como crime de lesa-majestade, passível de morte, pois se uma pessoa pecasse contra Deus, toda a Sua ira recairia sobre o reino. Tinha-se, assim, uma excelente justificativa para o policiamento da vida pessoal dos seus súditos. Caso um fizesse algo que desagradasse à Deus (=Igreja=Coroa), a punição imediata era exigida para o bem de todos.

Claro que, em tempos de cura gay (sic), acusações gratuitas de pedofilia em exposições artísticas, de censura às formas de criatividade e de pensamento, não podemos dizer que estas práticas tenham chegado a um termo. Esse policiamento ostensivo é uma forma de se afirmar "quem manda" ...

Aliás, fazer uma crítica aos processos históricos e às técnicas e dispositivos de heternormatização é, também, fazer uma crítica à própria academia.

Se a homofobia nasce no seio da igreja, ela aumenta e se consolida na academia, juntamente com o racismo. A nuvem discursiva desde a qual o indígena não seria apto ao trabalho, fato "cientificamente comprovado" na exposição antropológica brasileira de 1882 é a mesma que comprovará, também cientificamente, que a sífilis é um mal negro e que avós tuberculosos podem passar "degenerescência" para seus netos (em um discurso comum entre meados dos séculos XIX e XX, mas que retorna com força nestes tempos sombrios nos quais o Brasil se encontra). A pederastia era um mal a ser expurgado das aldeias, para o bem da nação que se buscava consolidar e construir. Caberiam aos indígenas serem não mais bons súditos, mas bons cidadãos, de família, pagadores de impostos, 
subempregados, exploráveis. Quando um indígena nasce com determinada genitália, a ele será dado um nome de menino ou de menina, trabalhos de homem ou de mulher, roupa de homem ou de mulher, corte de cabelo de homem ou de mulher,... mas não qualquer homem ou mulher: de homem ou mulher não indígenas. Não se trata apenas de violentá-los em sua sexualidade, mas também em sua indianidade. Daí a acusação contraditória mas ainda frequente, de que indígenas fora do padrão hetero imposto pela colonização seriam menos indígenas do que os indígenas bons cristãos e pais de família ${ }^{10}$.

Suponho, como tenho feito questão de salientar, que várias dessas questões não se restrinjam apenas aos povos indígenas. A mesma nuvem discursiva que lhes impôs determinado padrão de sexualidade segue firme e forte. A questão, como disse antes, "é quem manda". Falar em sexualidade indígena incomoda porque deixa claro como moral e poder caminham juntos, muitas vezes com a participação e conivência silenciosa de cientistas e religiosos bem-intencionados.

Meu esforço, como disse antes - e é esse esforço que espero compartilhar com vocês - não é mais tentar entender "a" homossexualidade indígena como fenômeno, mas o que podemos compreender a partir dela. Ela me ensina, ao problematiza-la, que o colonialismo ainda existe e persiste. Que nossos aparatos discursivos-epistêmicos são insuficientes. Que a mera reprodução de categorias acadêmicas importadas dos grandes centros e difusão do conhecimento servem como ponto de partida, mas não devemos nos deixar colonizar, limitar e disciplinar por elas. Que às vezes os pontos obscuros são mais interessantes do que a mera reprodução do que é tantas vezes dito. Que as fronteiras oferecem um excelente ponto de partida e que estar nas periferias é um ato político. Mais que isso. Resistir ao discurso da moral não é se insurgir contra uma religião, mas contra um aparato de poder que opera pelo apagamento. Que a gênese da censura, dos silenciamentos, da intolerância está na gênese do próprio modelo de Estado e imbuído no espírito de cada autoproclamado "cidadão de bem" de plantão. Ou será que essas pessoas, posando de verde e amarelo nas manifestações pelo impeachment sabem que o losango na bandeira brasileira significava, para os positivistas, os quatro papéis que cabe à mulher ocupar em casa (mãe, filha, irmã e esposa?). Nossa república, positivista, é também misógina e efeminóbica.

Neste sentido, o queer oferece um lugar de resistência, mas para isso temos que deixar de aprender que nosso lugar é errado, que moramos longe, que

${ }^{10}$ Para um desenvolvimento das questões apresentadas nas últimas páginas, cf. Fernandes, 2015. 
nosso sotaque é "engraçadinho" ou "bonitinho", que nossa cor é escura demais e nossa sexualidade, errada; que na minha cidade não tem onças passando e que temos mais a oferecer do que mão de obra, carnaval, fotos nas florestas ou locais onde usinas possam ser construídas.

O que podemos aprender, por exemplo, desde textos queer africanos, do pensamento feminista indiano, das críticas two-spirit? Em que medida a reprodução de um conjunto de autores - quase sempre situados na França ou na Califórnia - nos permitem contrapor de forma radical movimentos de direita que insistem em chamar a educação para a diversidade sexual de "ideologia de gênero"? Até que ponto pode-se levar adiante uma empreitada deste tipo sem levar em consideração o papel de igrejas neopentecostais no interior do Brasil?

É possível, por exemplo, compreender os casos de agressão motivados por religião no País sem levar em conta a forma como a homofobia tem se naturalizado em comentários de portais de notícias e redes sociais? Talvez seja a hora, como alguns colegas da Amazônia temos defendido, de um queer caboclo ${ }^{11}$, sendo caboclo aqui empregado não como adjetivo, mas como verbo, no sentido de pensar uma lógica que opere não a partir da lógica hegemônica, assentadas e estáveis, mas a partir de uma visão epistemopoliticamente motivada de lógicas-outras.

Além disso, é necessária uma agenda de superação da divisão de trabalho acadêmico no Brasil, desde a qual os centros (localizados no centro-sul) fornecem teoria - quase sempre reproduzindo autores dos Centros (localizados no norte epistêmico), enquanto ao "resto", cabe fornecer "experiências". O que movimentos feministas ou LGBT na Amazônia ou no campo, por exemplo, podem nos dizer sobre garimpo, desenvolvimento, PAC, grandes obras, exploração sexual nas fronteiras do capitalismo brasileiro - e vice-versa? É possível recuperar a voz desses atores sem filtrá-la em nossa prática acadêmica, neutra, objetiva, externa, e, no fim das contas, morna? Narrar simplesmente suas trajetórias para corroborar a hipótese pensada por algum autor pop, como se nosso contexto fosse o de um café às margens do Sena ou em Nova Iorque, e não de um pós-golpe institucional branco e heteropratriarcal é, em última instância, o de cumplicidade com o status quo e com a estrutura de poder que lhe é subjacente. É hora de subversão. É hora de insubmissão. Hora de sublevação. Hora de sair dos debates e partir para o embate.

${ }^{11}$ Cf. Fernandes e Gontijo, 2016. 


\section{Referências Bibliográficas}

ANZALDUA, Gloria. "La conciencia de la mestiza: rumo a uma nova consciência". Rev. Estud. Fem. vol.13, n.3, pp. 704-719. 2005.

CÉSAIRE, Aimé. Discurso sobre o colonialismo. Lisboa: Livraria Sá da Costa Editora. 1978.

FANON, Frantz. Pele negra, máscaras brancas. Salvador: EDUFBA, 2008.

. "Racismo e cultura". SANCHES, Manuela Ribeiro (Org.). Malhas que os impérios tecem: textos anticoloniais, contextos pós-coloniais. Lisboa: Edições 70. Pp. 273-285. 2011.

FERNANDES, Estevão Rafael. "Ruptura epistêmica, decolonialidade e povos indígenas: reflexões sobre saberes-outros". DANNER, Fernando; DANNER, Leno Francisco. (Org.). Ensino de Filosofia, Gênero e Diversidade: Pensando o Ensino de Filosofia na Escola. p. 52-72. Porto Alegre: Editora Fi, 2014.

"Decolonizando sexualidades: Enquadramentos coloniais e homossexualidade indígena no Brasil e nos Estados Unidos". Tese de Doutorado defendida no Programa de Pós-Graduação em Ciências Sociais (Estudos Comparados sobre as Américas). Brasília: Ceppac/UnB. 2015.

"Algumas inflexões sobre o Brasil: Um experimento epistêmico radical desde Abya Ayala". REALIS, Revista de Estudos AntiUtilitaristas e Poscoloniais., v. 6, p. 83-101, 2016.

"Existe índio gay?": a colonização das sexualidades indígenas no Brasil. Curitiba: Prismas, 2017.

FERNANDES, Estevão Rafael; GONTIJO, Fabiano. "Diversidade sexual e de gênero e novos descentramentos: Um manifesto queer caboclo". Amazônica: Revista de Antropologia, v. 8, p. 14-22, 2016.

MOTT, Luiz. "Etnohistoria de la homosexualidad en América Latina". OCHOA, Juan Andrés Pizzani (Org.). Crítica a los discursos sobre las prácticas sexuales de los pueblos originarios. Caracas: Fundación Editorial el perro y la rana. 2015. 